\title{
Formation of a Carbon Interphase Layer on SiC Fibers Using Electrophoretic Deposition and Infiltration Methods
}

\author{
Pipit Fitriani, Amit Siddharth Sharma, Sungho Lee, and Dang-Hyok Yoon ${ }^{\dagger}$ \\ School of Materials Science and Engineering, Yeungnam University, Gyeongsan 712-749, Korea \\ (Received June 29, 2015; Revised July 14, 2015; Accepted July 14, 2015)
}

\begin{abstract}
This study examined carbon layer coating on silicon carbide ( $\mathrm{SiC}$ ) fibers by utilizing solid-state and wet chemistry routes to confer toughness to the fiber-reinforced ceramic matrix composites, as an alternative to the conventional pyrolytic carbon (PyC) interphase layer. Electrophoretic deposition (EPD) of carbon black nanoparticles using both AC and DC current sources, and the vacuum infiltration of phenolic resin followed by pyrolysis were tested. Because of the use of a liquid phase, the vacuum infiltration resulted in more uniform and denser carbon coating than the EPD routes with solid carbon black particles. Thereafter, vacuum infiltration with controlled variation in phenolic resin concentration, as well as the iterations of infiltration steps, was improvised to produce a homogeneous carbon coating having a thickness of several hundred nanometers on the $\mathrm{SiC}$ fiber. Conclusively, it was demonstrated that the carbon coating on the SiC fiber could be achieved using a simpler method than the conventional chemical vapor deposition technique.
\end{abstract}

Key words : Carbon, Silicon carbide, Composites, Electrophoretic deposition

\section{Introduction}

S iC-based ceramics are considered one of the most attractive materials for high temperature applications, being used in areas such as structural components for gas turbines, heat exchangers, and nuclear reactors, owing to their excellent thermal and mechanical properties. ${ }^{1-4)}$ Because monolithic $\mathrm{SiC}$ shows brittle fracture behavior, $\mathrm{SiC}$ fiber-reinforced $\mathrm{SiC}$ matrix composites $\left(\mathrm{SiC}_{\mathrm{f}} / \mathrm{SiC}\right)$ have been proposed to mitigate this problem. ${ }^{5)}$ Among the several commercially available SiC fibers, Tyranno Fiber SA grade (Ube Industries, Ltd, Japan) is considered to be best for reinforcement because of its high strength and excellent heat resistance up to $2200^{\circ} \mathrm{C}$ in an inert atmosphere. ${ }^{6)}$ Moreover, Tyranno Fiber SA exhibited better static fatigue and longer rupture time than Hi-Nicalon Type S fiber (NGS Advanced Fibers Co., Ltd, Japan) because of its lower amount of free carbon ( 2 at.\%) and coarser grains $(\sim 50-100 \mathrm{~nm}){ }^{6}{ }^{6}$

To confer damage tolerance to $\mathrm{SiC}_{\mathrm{f}} / \mathrm{SiC}$, the presence of weak interphase between the fiber and matrix is essential. This is normally obtained by the deposition of a pyrolytic carbon $(\mathrm{PyC})$. When a crack is propagating through a composite, the weak interphase enhances toughness by a variety of mechanisms, such as interfacial de-bonding, fiber pullout, and crack deflection. Thus far, chemical vapor deposition (CVD) is mainly used for the formation of a PyC layer,

${ }^{\dagger}$ Corresponding author : Dang-Hyok Yoon

E-mail : dhyoon@ynu.ac.kr

Tel : +82-53-810-2561 Fax : +82-53-810-4628 which normally gives a homogeneous and uniform coating. On the other hand, CVD is an expensive and time-consuming process using toxic reactant gases. ${ }^{7,8)}$ Therefore, the development of an alternative method for $\mathrm{PyC}$ coating that is simpler and more cost-effective than CVD is desirable.

For this, both the electrophoretic deposition (EPD) of carbon black particles and coating of phenolic resin on the $\mathrm{SiC}$ fiber followed by pyrolysis were considered. ${ }^{4,9)}$ EPD is a colloidal process which involves the migration of charged particles to the counter-electrode in a suspension under an electric field. EPD using a direct current (DC-EPD) in organic solvents instead of water has been used conventionally due to water electrolysis under a DC electric field. On the other hand, the recently introduced EPD using an asymmetric alternating current (AC-EPD) has been used to deposit many kinds of ceramic particles in aqueous systems, while minimizing the decomposition of water. ${ }^{10-12)}$ Because the velocity of a particle shows a non-linear dependence on the AC electric field, the net particle movement for deposition occurs under an asymmetric AC electric field, suppressing water decomposition. ${ }^{13)}$ Although some studies used DCEPD to deposit a carbon layer from a carbon black suspension, ${ }^{14,15)}$ to the best of the authors' knowledge, there are no reports of the application of AC-EPD. Therefore, in this study, both DC- and AC-EPD were tested and compared for the formation of a carbon layer from a carbon black suspension containing both a binder and dispersant. Periodic ultrasonic pulses were applied during EPD to infiltrate the carbon black particles deep inside the $\mathrm{SiC}$ preform.

Another alternative technique used in this study was the infiltration of phenolic resin into an $\mathrm{SiC}$ fabric followed by 
pyrolysis. Phenolic resin is a heat-cured plastic formed from a reaction between carbon-based alcohol and an aldehyde, and it is being used for a wide range of applications. ${ }^{16,17)}$ The vacuum infiltration technique, which uses a pressure gradient, was adopted for the efficient infiltration of phenolic resin into the woven $\mathrm{SiC}$ fabric. ${ }^{18,19)}$ This study examined the above three different techniques for the formation of a carbon layer on the $\mathrm{SiC}$ fibers, as an alternative method to the conventional pyrolytic carbon $(\mathrm{PyC})$ interphase layer.

\section{Experimental Procedure}

\section{1. $D C$ - and $A C-E P D$}

Two-dimensionally woven Tyranno-SA3 SiC fabric, with a fiber diameter of $7.5 \mu \mathrm{m}$ and 1600 fibers per yarn, was used as a preform. Prior to use, the polyethylene oxide sizing agent was removed by immersing the fabric in boiling water for 10 minutes. For DC-EPD, a well-dispersed suspension, containing $2 \mathrm{wt} \%$ carbon black particles (Hiblack, Orion Engineered Carbons, Korea) with a mean particle size of 35 $\mathrm{nm}$, was prepared in ethanol by adding $5 \mathrm{wt} \%$ polyester/ polyamine co-polymeric dispersant (Hypermer KD1, ICI, UK) and 5 wt\% PVB binder resin (Butvar B-98, MW = $55,000 \mathrm{~g} / \mathrm{mol}$, Solutia, USA). The suspension was ball-milled for 24 hours using $6 \mathrm{~mm} \mathrm{SiC}$ balls to ensure dispersion. The zeta potential of the suspension was measured using an electroacoustic-type zeta potential analyzer (Zeta Probe, Colloidal Dynamics, USA) by varying the operational $\mathrm{pH}$ of the suspension.

A disc-shaped $\mathrm{SiC}$ fabric with a $5 \mathrm{~cm}$ diameter was placed between the dual stainless steel electrodes dipped in a carbon black suspension, as shown in Fig. 1. DC-EPD was then performed under an electric field of $500 \mathrm{~V} / \mathrm{m}$ for 60 minutes with the application of $10 \mathrm{~W}$ ultrasonic pulses (HD 2070, Bandelin, Germany). The distance between each electrode and the $\mathrm{SiC}$ fabric was $2 \mathrm{~cm}$. By considering the positive zeta potential of the carbon black particles in the suspension, the SiC fabric was connected to the negative power source, and the dual stainless steel electrodes were connected to the positive source. After drying the infiltrated fabrics at $80^{\circ} \mathrm{C}$, the samples were heat-treated to $600^{\circ} \mathrm{C}$ for 2 $\mathrm{h}$ in an $\mathrm{N}_{2}$ atmosphere. The experimental conditions for DCEPD were chosen based on the previous report ${ }^{4)}$ and further preliminary tests.

For AC-EPD, an aqueous carbon black suspension was prepared by adding $0.5 \mathrm{wt} \%$ each of ammonium polycarboxylate (Cerasperse 5468CF, San Nopco, Korea) dispersant and water-soluble acrylic binder (WB4101, Polymer Innovations, USA). Ball milling and zeta potential measurement were then performed, as described above. AC-EPD was then conducted using the apparatus shown in Fig. 1 after switching the polarity from that of a DC-EPD because of the negative zeta potential of the carbon black particles for AC-EPD. Instead of a DC-power supply, however, a programmable function generator (3322A, Agilent, USA), power amplifier (PZD 700A M/S, Trek, USA), and digital oscilloscope (DSO-
X 2002A, Agilent, USA) were used for AC signal generation and EPD for a disc-shaped SiC fabric using a dual electrode system. A square-shaped asymmetric $100 \mathrm{~Hz}$ AC signal with an asymmetry factor of 4 and a peak-to-peak voltage of $20 \mathrm{~V}$ was applied for 60 minutes for AC-EPD to the aqueous suspension at $\mathrm{pH}=3$, based on a preliminary test, ${ }^{20)}$ while applying $10 \mathrm{~W}$ ultrasonic pulses with a frequency of $1 \mathrm{~Hz}$ to enhance the degree of phenolic resin infiltration into the $\mathrm{SiC}$ preform. The inset in Fig. 1 shows the waveforms of the voltage signals for DC- and AC-EPD.

\subsection{Vacuum infiltration}

After diluting a phenolic resin (HiRENOL, Kolon Industries, Korea) to $5 \mathrm{wt} \%$ in six different kinds of solvents (methanol, ethanol, propanol, butanol, pentanol, and ethylene glycol), the phenolic resin solution was infiltrated into five layers of $\mathrm{SiC}$ fabrics by pressure gradient using the vacuum infiltration apparatus shown in Fig. 2. The experimental setup was composed of an outer chamber, vacuum pump, and inner vessel, which was divided by a spacer to place five layers of round-shaped $\mathrm{SiC}$ fabrics. After placing the fabrics

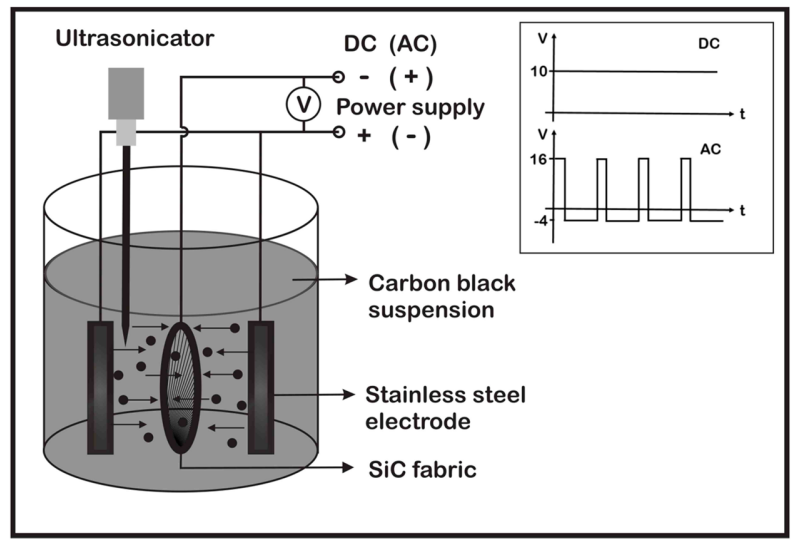

Fig. 1. Schematic diagram of the experimental setup for carbon black infiltration using DC- and AC-EPD. Modified from a previous report. ${ }^{21)}$

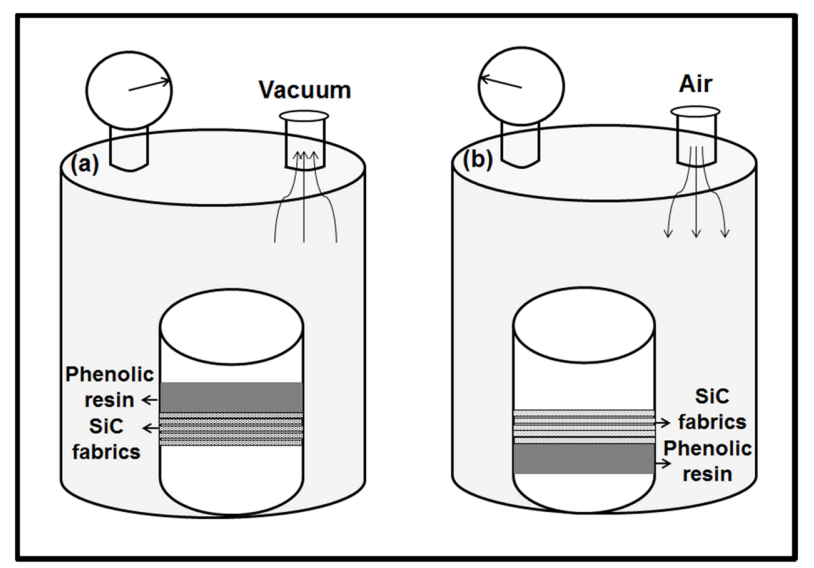

Fig. 2. Schematic diagram of the experimental setup for vacuum infiltration during vacuum (a) increase and (b) release. Modified from a previous report. ${ }^{19)}$ 
in the middle of the inner vessel with the phenolic resin solution on top, the vacuum was released slowly to atmospheric pressure when the pressure reached $0.1 \mathrm{~Pa}$. Owing to the pressure difference between the top and bottom of the inner vessel during this release, the solution was passed through the fabrics, infiltrating the gaps of the fibers. The infiltrated fabrics were then centrifuged at $200 \mathrm{rpm}$ to remove the extra phenolic resin filling the voids of the fabrics. Vacuum infiltration was performed at various concentrations of phenolic resin solution in methanol and infiltration repetitions because methanol was the optimal solvent for the coating. To convert the phenolic resin to carbon, pyrolysis was performed in a tube furnace at $600^{\circ} \mathrm{C}$ for 1 hour at a heating rate of $5^{\circ} \mathrm{C} / \mathrm{min}$ in an $\mathrm{N}_{2}$ atmosphere. The thermal decomposition behavior of the phenolic resin was also examined by thermo-gravimetric analysis (TGA: SDT Q600, TA Instruments, USA). The viscosity of each phenolic resin solution at $20^{\circ} \mathrm{C}$ was measured using a computer-controlled viscometer (DV-II+ Pro, Brookfield, MA, USA) equipped with a small sample adapter with a SC4-18 spindle at various shear rates. The microstructure of the infiltrated fabrics was observed by scanning electron microscopy (SEM; Hitachi S-4200).

\section{Results and Discussion}

\subsection{DC-and AC-EPD of the carbon black particles}

Figure 1 presents the experimental setup used for carbon black particle infiltration into the $\mathrm{SiC}$ fabric by $\mathrm{DC}$ - and $\mathrm{AC}$ EPD combined with ultrasonication. The apparatus was composed of dual stainless steel positive electrodes to enhance the degree of deposition from both sides and a negative electrode connected to the $\mathrm{SiC}$ fabric placed in the middle of the vessel. An ultrasonic tip was placed into the suspension, which released $10 \mathrm{~W}$ ultrasonic pulses with a 1 second cycle to accelerate the carbon black infiltration into the deep voids of the preform. The only difference in the DCand AC-EPD apparatus was the power supply, where a sole DC power supply was used for DC-EPD, whereas the combinations of function generator, amplifier, and oscilloscope were used for AC-EPD.

As mentioned previously, a solvent-based system is used preferentially for DC-EPD because of the decomposition of water under a DC electric field, whereas AC-EPD can use an aqueous system owing to the minimized water electrolysis under asymmetric AC electric field. Fig. 3 (a) and (b) shows the zeta potential behavior of a carbon black suspension in ethanol (for DC-EPD) and water (for AC-EPD), respectively, as a function of the operational $\mathrm{pH}$ with/without a binder and dispersant. Both measurements were performed using an electroacoustic technique, which is adequate for measuring the zeta potential for small particles because the carbon black particles were very fine with a mean particle size of $35 \mathrm{~nm}$. The higher zeta potential confers larger repulsion between the particles in terms of the electrostatic mechanism, whereas the sign of the zeta poten-
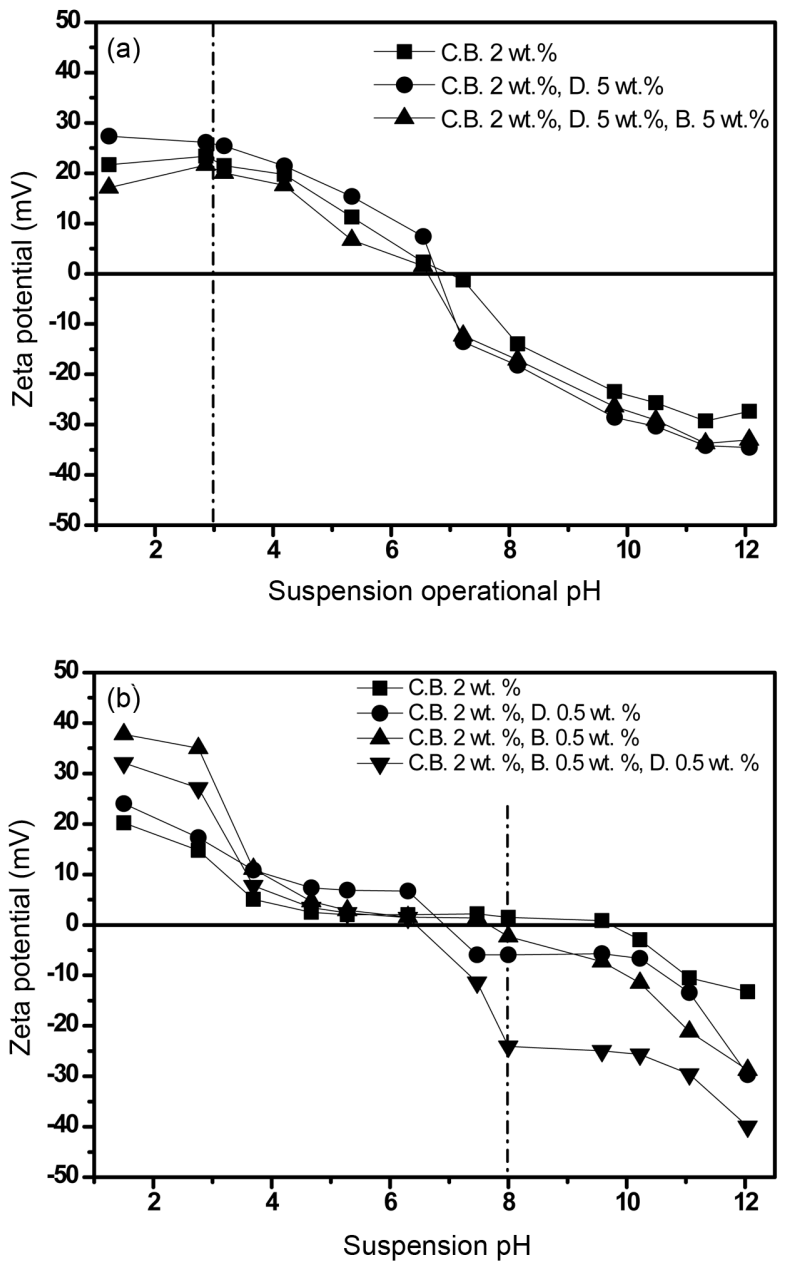

Fig. 3. Zeta potential of the carbon black suspensions with/ without binder and dispersant in (a) ethanol and (b) water as a function of the operational $\mathrm{pH}$.

tial determines the direction of particles moving during EPD. For the ethanol-based suspension shown in Fig. 3 (a), the zeta potential decreased with increasing operational $\mathrm{pH}$ due to the increased concentration of hydroxyl ions $\left(\mathrm{OH}^{-}\right)$, regardless of the presence of a binder or dispersant. Because higher zeta potential leads to higher mobility of particles, the suspension containing both the binder and dispersant with the operational $\mathrm{pH}=3$ was chosen for DC-EPD, which had a positive zeta potential of $25 \mathrm{mV}$. Five wt\% of a polymeric dispersant was added to maximize the dispersion stability via steric stabilization, whereas the binder was added to enhance the adhesion of carbon black powder to the surface of the $\mathrm{SiC}$ fabric preform. The effects of the dispersant and binder addition on the zeta potential were found to be insignificant in this ethanol-based system, as shown in Fig. 3(a). On the other hand, the zeta potential of the carbon black particles in an aqueous system was affected by the co-presence of a binder and dispersant, as shown in Fig. 3(b). Therefore, $\mathrm{pH}=8$ was chosen for ACEPD, where a zeta potential of $-28 \mathrm{mV}$ could be achieved. 
Although the AC power source oscillates its polarity, the $\mathrm{SiC}$ fabric was connected to the positive electrode because of the asymmetric AC signal to maximize the degree of infiltration. The iso-electric points, where the zeta potential $=0$, were a $\mathrm{pH}$ of approximately 6 for both systems.

Figure 4 shows SEM images of the SiC fibers before and after EPD. Because the as-received SiC fabrics have small gaps between the fibers within a yarn, as shown in Fig. 4(a), the efficient infiltration of carbon black particles into the deep inter-fiber voids is essential for coating each $\mathrm{SiC}$ fiber uniformly, as shown in Fig. 4(b). Fig. 4(c) and (d) show SEM images of the carbon coating layers formed by DC- and ACEPD after pyrolysis at $600{ }^{\circ} \mathrm{C}$, respectively. Although the vigorous migration of carbon black particles was observed during $\mathrm{EPD}$, the resulting carbon coating layers on the $\mathrm{SiC}$ fiber surface were inhomogeneous in both methods. The coating layer revealed the rough agglomeration of carbon black particles instead of a smooth surface, which might be inevitable because of the use of a solid phase as a starting material. A simple comparison of the coating layer morphology showed that AC-EPD resulted in a more uniform coating than DC-EPD, indicating the potential feasibility of the eco-friendly AC-EPD using an aqueous system.

\subsection{Vacuum infiltration of the phenolic resin fol- lowed by pyrolysis}

To identify a more suitable method for the formation of a carbon layer than the EPD of carbon black particles, infiltration using a phenolic resin solution followed by pyrolysis was examined as an alternative. The utilization of a liquid phase instead of solid particles would be more desirable for forming a smooth carbon coating layer. Because the viscosity of pure phenolic resin was too high to infiltrate, i.e., 600 cPs at a shear rate of $132 \mathrm{~s}^{-1}$, dilution into a $5 \mathrm{wt} \%$ solution was performed using six different kinds of solvents. All solvents contained a hydroxyl ion $\left(\mathrm{OH}^{-}\right)$functional group, i.e., one $\mathrm{OH}^{-}$group for five kinds of alcohols and two $\mathrm{OH}^{-}$groups for ethylene glycol, because the presence of $\mathrm{OH}^{-}$in the sol-
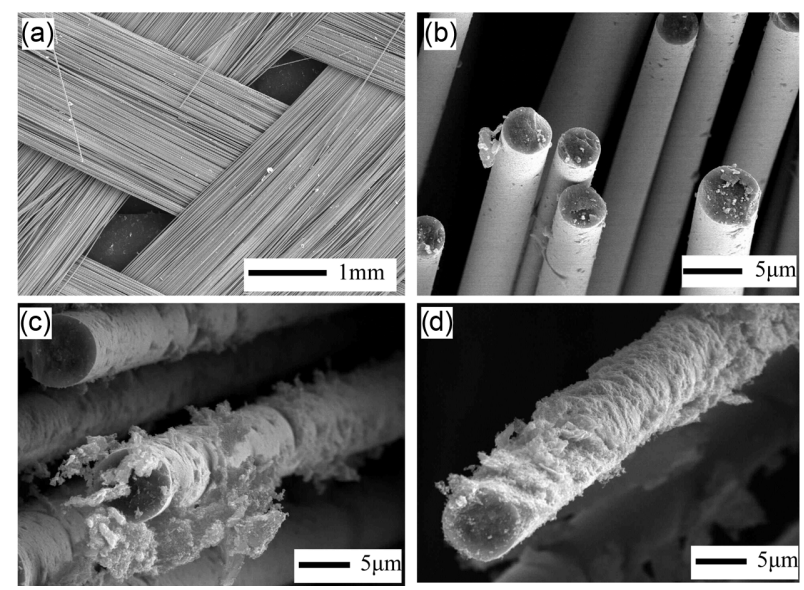

Fig. 4. SEM images of the (a) as-received $\mathrm{SiC}$ woven fabric, (b) bare SiC fibers, and the carbon black powdercoated SiC fibers using (c) DC- and (d) AC-EPD. vents is effective in reducing the viscosity of the pure phenolic resin. Based on the viscosity data shown in Fig. 5, all suspensions exhibited pseudo-plastic behavior. The phenolic resin in methanol exhibited the lowest viscosity, whereas that in ethylene glycol revealed the highest viscosity. Therefore, the viscosity of the phenolic resin solution is affected by the molecular weight of the solvent as well as the number of $\mathrm{OH}^{-}$groups, even though the difference in viscosity of phenolic resins dissolved in six types of solvents was not significant, as shown in Fig. 5.

A vacuum infiltration apparatus, which uses a forced pressure difference, was designed for effective infiltration of phenolic resin into the small inter-fiber voids, as shown in Fig. 2. After placing five layers of fabrics in the middle of the inner vessel with the phenolic resin on top, a vacuum was applied for infiltration, as shown in Fig. 2(a). When the vacuum level reached $0.1 \mathrm{~Pa}$, the air was released slowly. The slurry passed through the fabrics infiltrating between the gaps of the fibers due to the difference in force during release, as shown in Fig. 2(b).

TGA was performed to determine the optimal temperature for the conversion of phenolic resin to carbon, and the result is shown in Fig. 6. The weight loss up to $200^{\circ} \mathrm{C}$ was attributed to the loss of moisture, while the further weight loss at $400-650^{\circ} \mathrm{C}$ was due to degradation of the hydroxyl group and the decomposition of phenolic resin to carbon. ${ }^{22,23)}$ The last weight loss above $650^{\circ} \mathrm{C}$ was attributed to the thermo-oxidative reaction and the evaporation of the phenolic resin. Because most of the weight loss occurred up to $600^{\circ} \mathrm{C}$, the pyrolysis conditions were $600^{\circ} \mathrm{C}$ for 1 hour in an $\mathrm{N}_{2}$ atmosphere.

Figure 7 (a) and (b) shows SEM images of the carbon coating layer formed using a phenolic resin diluted to $5 \mathrm{wt} \%$ in methanol and butanol, respectively. The phenolic resin dissolved in methanol resulted in a uniform carbon coating layer on the SiC fiber, whereas that in butanol or other solvents did not produce a homogeneous coating. Therefore,

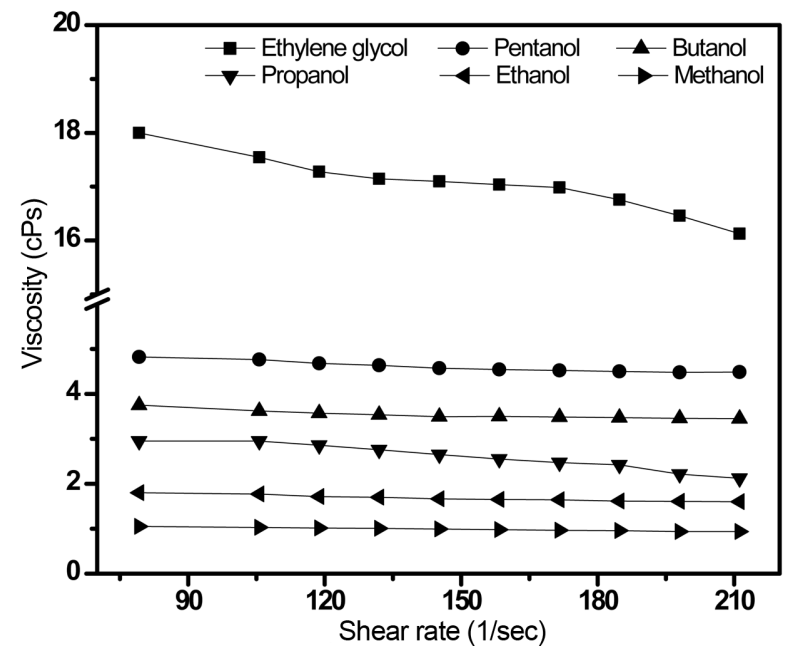

Fig. 5. Viscosity of the $5 \mathrm{wt} \%$ phenolic resin solution dissolved in various solvents. 


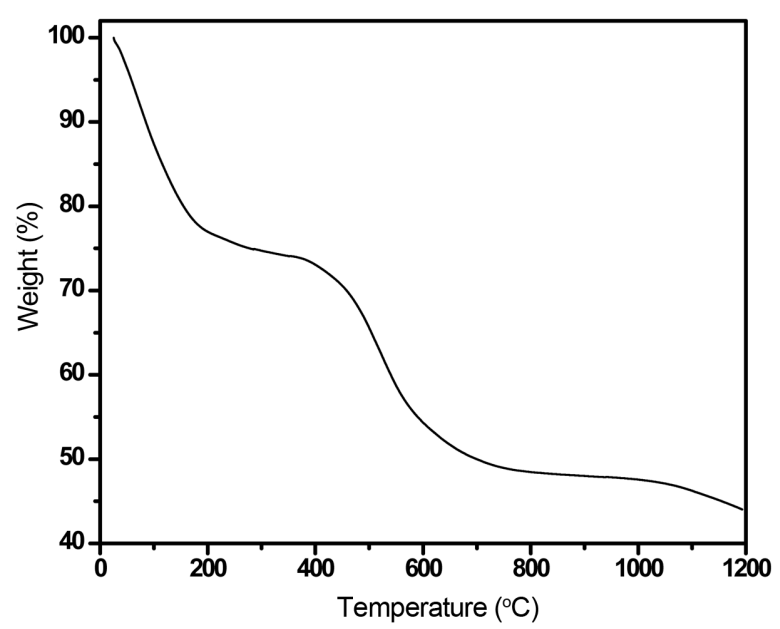

Fig. 6. Thermo-gravimetric behavior of the phenolic resin in $\mathrm{N}_{2}$ atmosphere.
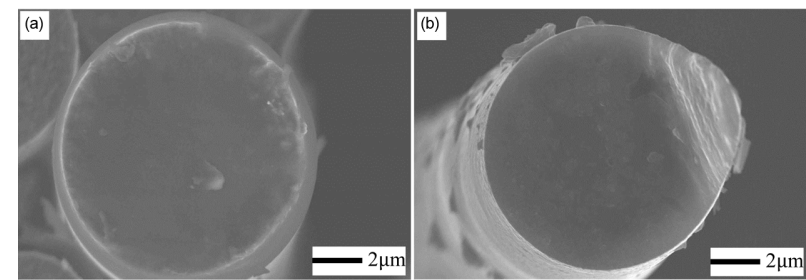

Fig. 7. SEM images of the $\mathrm{SiC}$ fiber after vacuum infiltration of phenolic resin dissolved in (a) methanol and (b) butanol followed by pyrolysis.

the property of the solvent appears to be very important for obtaining a uniform carbon coating layer, including the dissolvability of the phenolic resin. Among the six types of solvents, methanol tends to form the strongest hydrogen bond with the phenolic resin molecule because each hydroxyl group can provide a proton to form a hydrogen bond. Moreover, the hydrogen bond strength between the solvent and hydroxymethyl groups ( $\mathrm{R}-\mathrm{OH})$ in the phenolic resin decreased with increasing molecular weight because the polarity of solvent decreased with increasing hydrocarbon chain length. Consequently, the interaction force between the phenolic resin and methanol would be highest in terms of the hydrogen bonding strength and polarity. The other factor that might affect the formation of a uniform carbon layer is the degree of curing upon heat treatment, where fast and complete crosslinking is desirable. As suggested by Yan et al., the curing rate of the phenolic resin in methanol is the fastest compared to the other solvents containing a hydroxyl group. ${ }^{24)}$ Therefore, it appears that the phenolic resin solution in methanol produced the most homogeneous carbon coating layer on the SiC fiber, as shown in Fig. 7(a).

The thickness of the carbon coating layer on $\mathrm{SiC}$ fiber could be controlled by varying the concentration of phenolic resin dissolved in methanol and the number of infiltration, as shown in Fig. 8. For example, the mean carbon thickness $\left(t_{\mathrm{m}}\right)$ could be increased from 245 to $556 \mathrm{~nm}$ by repeating the
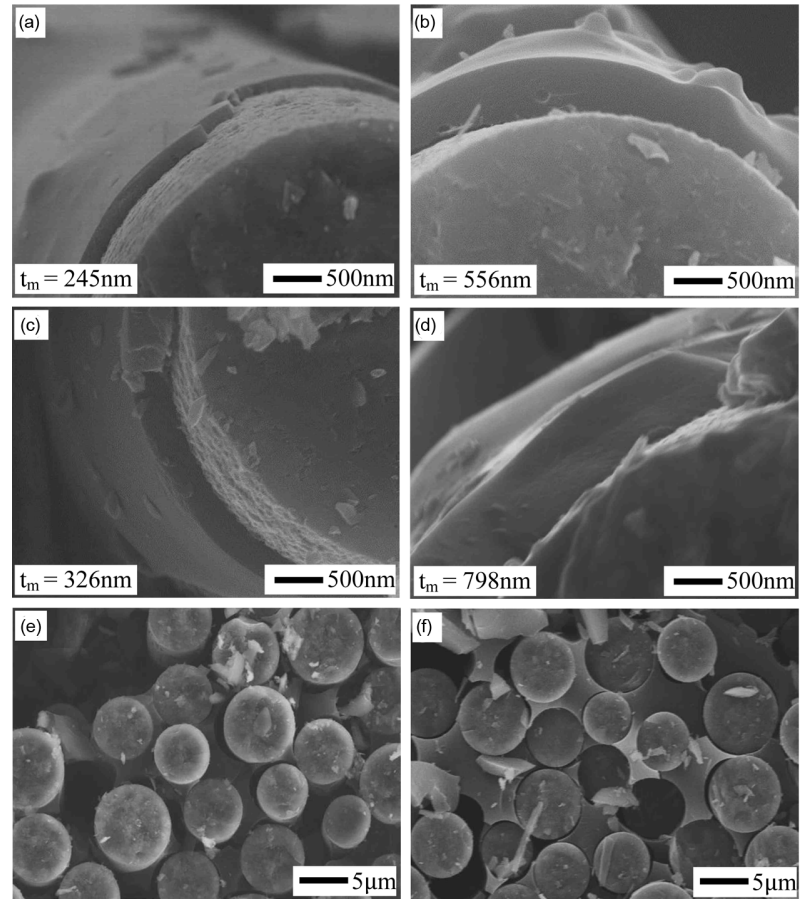

Fig. 8. SEM images of the carbon-coated $\mathrm{SiC}$ fibers after dissolving in methanol at different concentrations and infiltration repetitions: (a) $5 \mathrm{wt} \%, 1$ time, (b) $5 \mathrm{wt} \%$, 3 times, (c) $10 \mathrm{wt} \%, 1$ time, (d) $10 \mathrm{wt} \%, 3$ times, (e) $50 \mathrm{wt} \%$, 1 time and (f) $70 \mathrm{wt} \%, 1$ time.

infiltration from 1 to 3 times using a $5 \mathrm{wt} \%$ solution, whereas the PyC thickness using a $10 \mathrm{wt} \%$ solution increased from 326 to $798 \mathrm{~nm}$, respectively, as shown in Fig. 8(a) - (d). On the other hand, when the solution concentration was increased to 50 and $70 \mathrm{wt} \%$, it was unable to form a uniform carbon coating layer because of the excessive infiltration of phenolic resin into the inter-fiber voids, as shown in Fig. 8(e) and (f), respectively. Overall, the carbon layer thickness could be controlled by changing the solution concentration and the number of infiltrations, which is important for optimizing the interphase property between the matrix and fiber in the $\mathrm{SiC}_{f} / \mathrm{SiC}$ composites. According to a previous report, the minimum $\mathrm{PyC}$ thickness that could confer toughness to the composite was $600 \mathrm{~nm}$ due to the formation of a weak fiber-matrix interphase. ${ }^{5)}$

\section{Conclusions}

This study examined the formation of carbon interphase layer on $\mathrm{SiC}$ fibers, which can confer damage tolerance to $\mathrm{SiC}$ fiber-reinforced $\mathrm{SiC}$ matrix composites $\left(\mathrm{SiC}_{\mathrm{f}} / \mathrm{SiC}\right)$. When the direct deposition of carbon black particles using DC- and AC-EPD was tested by controlling the zeta potential of the particles in an ethanol- and water-based suspension, respectively, the inhomogeneous adhesion of carbon black particles to the $\mathrm{SiC}$ fiber was observed with both methods due to the use of solid particles as a starting material. On the other hand, vacuum infiltration using a phenolic resin diluted in 
various kinds of solvents followed by pyrolysis at $600{ }^{\circ} \mathrm{C}$ resulted in a uniform carbon coating layer over the $\mathrm{SiC}$ fiber only when methanol was used as a solvent. This was explained by the highest hydrogen bonding strength and the polarity of methanol among the six kinds of solvents used, which gives a strong interaction force between the solvent and phenolic resin, along with the fastest crosslinking upon pyrolysis. Moreover, the thickness of the carbon coating layer on the SiC fiber could be controlled within a thickness of $200-800 \mathrm{~nm}$ by changing the solution concentration and the number of infiltration steps. The fabrication of $\mathrm{SiC}_{\mathrm{f}} /$ $\mathrm{SiC}$ using a carbon-coated $\mathrm{SiC}$ fabric by vacuum infiltration of phenolic resin is currently underway.

\section{Acknowledgments}

This study was supported by the National R\&D Program funded by the Ministry of Science, ICT \& Future Planning, Republic of Korea (Grant no. 2014M1A7A1A02029408).

\section{REFERENCES}

1. S. J. Dapkunas, "Ceramic Heat Exchangers," Am. Ceram. Soc. Bull., 67 388-91 (1988).

2. Y. Takeda, "Development of High-Thermal-Conductive SiC Ceramics," Am. Ceram. Soc. Bull., 67 1961-63 (1988).

3. B. Riccardi, L. Giancarli, A. Hasegawa, Y. Katoh, A. Kohyama, R. H. Jones, and L. L. Snead, "Issues and Advances in $\mathrm{SiC}_{\mathrm{f}} / \mathrm{SiC}$ Composites Development for Fusion Reactors," J. Nucl. Mater., 329-333 56-65 (2004).

4. J. H. Lee, G. Y. Gil, and D. H. Yoon, "Fabrication of $\mathrm{SiC}_{\mathrm{f}}$ SiC Composites Using an Electrophoretic Deposition," J. Korean Ceram. Soc., 46 447-51 (2009).

5. A. Noviyanto and D. H. Yoon, "The Effects of Pyrolytic Carbon Interphase Thickness on the Properties of Hot-Pressed $\mathrm{SiC}_{\mathrm{f}} / \mathrm{SiC}$ Composites," J. Ceram. Process. Res., 13 392-97 (2012).

6. T. Ishikawa, Y. Kohtoku, K. Kumagawa, T. Yamamura, and T. Nagasawa, "High-Strength Alkali-Resistant Sintered SiC Fibre Stable to 2,200 ${ }^{\circ}$ C, Nature, 391 773-75 (1998).

7. K. Yoshida, Y. Aoyagi, H. Akimoto, T. Yano, M. Kotani, and T. Ogasawara, "Interfacial Control of Uni-Directional $\mathrm{SiC}_{\mathrm{f}}$ " $\mathrm{SiC}$ Composites Based on Electrophoretic Deposition and Their Mechanical Properties," Compos. Sci. Technol., 72 1665-70 (2012).

8. J. J. Brennan, "Interfacial Studies of Chemical-Vapor-Infiltrated Ceramic Matrix Composites," Mater. Sci. Eng. A, 216 203-23 (1990).

9. K. Raju and D. H. Yoon, "Electrophoretic Deposition of $\mathrm{BaTiO}_{3}$ in Aqueous Suspension Using Asymmetric Alternating Current," Mater. Lett., 110 188-90 (2013).

10. V.O. Kollath, Q. Chen, R. Closset, J. Luyten, K. Traina, S.
Mullens, A. R. Boccaccini, and R. Cloots, "AC vs. DC Electrophoretic Deposition of Hydroxyapatite on Titanium Substrate," J. Eur. Ceram. Soc., 33 2715-21 (2013).

11. A. Chavez-Valdez, M. Herrmann, and A.R. Boccaccini, "Alternating Current Electrophoretic Deposition (EPD) of $\mathrm{TiO}_{2}$ Nanoparticles in Aqueous Suspensions," J. Colloid Interphase Sci., 375 102-05 (2012).

12. A. Nold and R. Clasen, "Bubble-Free Electrophoretic Shaping from Aqueous Suspension with Micro Point-Electrode," J. Eur. Ceram. Soc., 30 2971-75 (2010).

13. B. Neirinck, J. Fransaer, O. Van der Biest, and J. Vleugels, "Aqueous Electrophoretic Deposition in Asymmetric AC Electric Fields (AC-EPD)," Electrochem. Commun., 1157 60 (2009).

14. K. Yoshida, K. Matsukawa, M. Imai, and T. Yano, "Formation of Carbon Coating on SiC Fiber for Two-Dimensional $\mathrm{SiC}_{f} / \mathrm{SiC}$ Composites by Electrophoretic Deposition," Mater. Sci. Eng. B, 161 188-92 (2009).

15. K. Yoshida, "Development of Silicon Carbide Fiber-Reinforced Silicon Carbide Matrix Composites with High Performance Based on Interfacial and Microstructure Control," J. Ceram. Soc. Jpn., 118 82-90 (2010).

16. Y. Chen, M. Yue, Z. H. Huang, and F. Kang, "Electrospun Carbon Nanofiber Networks from Phenolic Resin for Capacitive Deionization," J. Chem. Eng., 252 30-37 (2014).

17. F. T. Behrooz, B. M. Maher, and M. M. Shokrieh, "Mechanical Properties Modification of a Thin Film Phenolic Resin Filled with Nano Silica Particles," Comp. Mater. Sci., 96 411-15 (2015).

18. P. Yonathan, J. H. Lee, H. T. Kim, and D. H. Yoon, "Properties of $\mathrm{SiC}_{\mathrm{f}} / \mathrm{SiC}$ Composites Fabricated by Slurry Infiltration and Hot Pressing," Mater. Sci. Tech-Lond., 27 257-63 (2011).

19. P. Yonathan, J. H. Lee, H. T. Kim, D. H. Yoon, W. J. Kim, and J.Y. Park, "Improvement of $\mathrm{SiC}_{\mathrm{f}} / \mathrm{SiC}$ Density by Slurry Infiltration and Tape Stacking," Mater. Res. Bul., 44 211622 (2009).

20. K. Raju, H. W. Yu, and D. H. Yoon, "Aqueous Electrophoretic Deposition of SiC Using Asymmetric AC Electric Fields," Ceram. Int., 40 12609-12 (2014).

21. G. Y. Gi and D. H. Yoon, "Densification of $\mathrm{SiC}_{\mathrm{f}} / \mathrm{SiC} \mathrm{Com}-$ posites by Electrophoretic Infiltration Combined with Ultrasonication,” J. Ceram. Process. Res., 12 371-75 (2011).

22. M. Su, Z. Wang, H. Guo, X. Li, S. Huang, and L. Gan, "Silicon, Flake Graphite and Phenolic Resin-Pyrolyzed Carbon Based Si/C Composites as Anode Material for Lithium-Ion Batteries," Adv. Powder. Technol., 24 921-25 (2013).

23. S. Chow and P. R. Steiner, "Comparison of the Cure of Phenolic-Formaldehyde Novolac and Resol Systems by Differential Scanning Calorimetry," J. Appl. Polym. Sci., 23 1973-85 (1979).

24. Z. Yan, L. Yujian, H. Qi, and H. Zhewen, "Effect of Solvent on the Chain Conformation and Cure Behavior of Phenolic Resin,” J. Appl. Polym. Sci., 108 3009-15 (2008). 